\title{
A Low-Power Voltage Reference Cell with a 1.5 V Output
}

\author{
Mir Mohammad Navidi and David W. Graham * \\ Lane Department of Computer Science and Electrical Engineering, West Virginia University, \\ Morgantown, WV 26506, USA; minavidi@mix.wvu.edu \\ * Correspondence: david.graham@mail.wvu.edu; Tel.: +1-304-293-9692
}

Received: 28 March 2018; Accepted: 11 June 2018; Published: 14 June 2018

\begin{abstract}
A low-power voltage reference cell for system-on-a-chip applications is presented in this paper. The proposed cell uses a combination of standard transistors and thick-oxide transistors to generate a voltage above $1 \mathrm{~V}$. A design procedure is also presented for minimizing the temperature coefficient (TC) of the reference voltage. This circuit was fabricated in a standard $0.35 \mu \mathrm{m}$ complementary metal-oxide-semiconductor (CMOS) process. It generates a $1.52 \mathrm{~V}$ output with a TC of $42 \mathrm{ppm} /{ }^{\circ} \mathrm{C}$ from $-70{ }^{\circ} \mathrm{C}$ to $85^{\circ} \mathrm{C}$ while consuming only $1.11 \mu \mathrm{W}$.
\end{abstract}

Keywords: voltage reference; low power; temperature dependence; CMOS integrated circuits; analog integrated circuits

\section{Introduction}

Voltage reference circuits are critical building blocks that are used to generate a stable voltage across a wide range of temperatures. As newer CMOS technology nodes are providing lower threshold voltages and reduced supply voltages, the main emphasis of recent designs has been to generate a low reference voltage (especially less than $1 \mathrm{~V}$ ) using a low supply voltage. Many good designs have been developed that provide these sub- $1 \mathrm{~V}$ reference voltages using very low power (e.g., [1-6]).

However, many applications still exist that require reference voltages greater than $1 \mathrm{~V}$ but also consume very little power. For example, our intended application of a low-power voltage reference cell is within a reconfigurable analog/mixed-signal platform that is capable of synthesizing a wide variety of extremely low-power circuits and systems [7]. Most applications developed on our custom Reconfigurable Analog/Mixed-Signal Processor (RAMP) consume approximately 10-20 $\mu \mathrm{W}$ and are capable of sophisticated processing (e.g., voice-activity detection, speech processing, infrared proximity detection, etc.). Therefore, the biasing circuitry should consume significantly less power than the signal-processing circuitry in order to reap the benefits of the low-power operation of the RAMP. As part of the biasing structure, this RAMP system requires a reference voltage between 1-2 V. While the low-voltage output of a sub- $1 \mathrm{~V}$ reference could be scaled to the necessary above- $1 \mathrm{~V}$ value for our application, the additional circuitry necessary to amplify/scale the voltage would add to the overall complexity and power consumption.

While a number of good above- $1 \mathrm{~V}$ designs have been presented, there has been a severe trade-off between having a low temperature coefficient (TC) and low power consumption. Most above- $1 \mathrm{~V}$ reference circuits that achieve good TCs consume too much power for many ultra-low-power applications. For example, Refs. [8-11] are all able to achieve a TC $<100 \mathrm{ppm} /{ }^{\circ} \mathrm{C}$ but consume from $35 \mu \mathrm{W}$ to $0.648 \mathrm{~mW}$, which is far too much power for our RAMP system. Other above- $1 \mathrm{~V}$ voltage reference circuits have been able to simultaneously maintain a low TC and power consumption less than $10 \mu \mathrm{W}$ by using devices that are not available in standard CMOS processes, such as anti-doped NMOS devices [12], native NMOS devices [13], and NPN transistors [14-16]. 
In this paper, we present a voltage reference cell that is able to simultaneously achieve a low $\mathrm{TC}$ and low power consumption over a large range of temperatures. Our voltage reference cell has been fabricated in a standard $0.35 \mu \mathrm{m} C M O S$ process and is capable of generating a reference voltage greater than $1 \mathrm{~V}$ with a $\mathrm{TC}<110 \mathrm{ppm} /{ }^{\circ} \mathrm{C}$ and single $\mu \mathrm{W}$ power consumption over a wide range of temperatures. To minimize power consumption, we operate the transistors in the subthreshold regime. We also selectively use I/O thick-oxide transistors due to their higher threshold voltage and temperature dependence than standard thin-oxide devices. Specifically, the larger threshold voltage of thick-oxide devices, and a corresponding larger $V_{g s}$ for a given current level, allows us to raise the output voltage to a higher value than can be achieved using similar techniques employing only thin-oxide devices [2], while also using a low number of transistors. In addition, the higher temperature dependence of the thick-oxide devices' threshold voltages are used to counter-balance the positive temperature-dependent terms from the rest of the circuit to achieve a low TC. Furthermore, we have created an output voltage that is a function of the ratio of resistors, and thus the temperature-dependent terms due to the resistors largely cancel out. Additionally, this resistive ratio, along with the circuit topology, permits an easy design procedure to minimize the TC.

The remainder of this paper is organized as follows. Section 2 describes the operation of the proposed circuit. Section 3 provides details on how to minimize the TC. Section 4 presents the experimental results of the proposed circuit. Finally, Section 5 presents the conclusion of this work.

\section{Principle of Operation}

In this section, we present a voltage reference circuit that uses both standard transistors and $5 \mathrm{~V}$ I/O transistors to generate a low-TC output voltage while consuming low power. The complete voltage reference circuit is shown in Figure 1. All the transistors used in this circuit are standard (thin-oxide) transistors except for $M_{t 1}$ and $M_{t 2}$ that are thick-oxide transistors (5 V I/O devices). Two resistors are used in this circuit-one to generate the reference current $\left(R_{C}\right)$ and the other to generate the final reference voltage $\left(R_{\text {out }}\right)$.

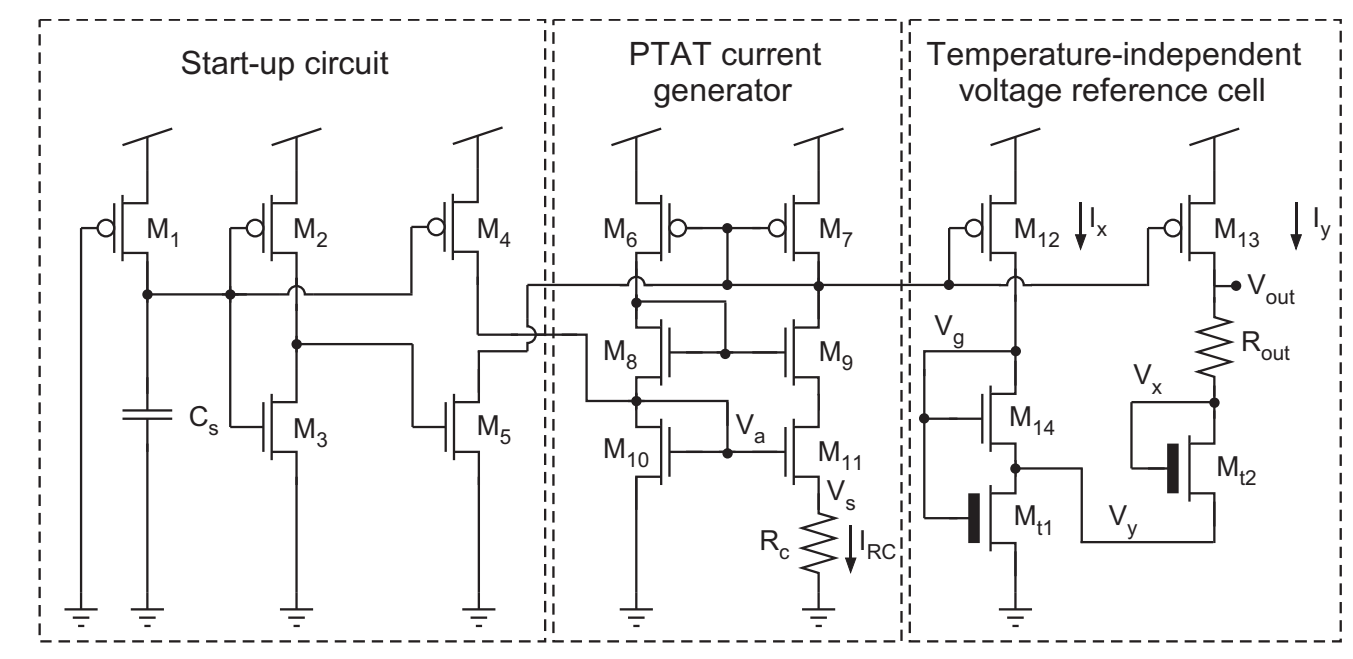

Figure 1. Schematic diagram of the proposed voltage reference cell. $M_{t 1}$ and $M_{t 2}$ are thick-oxide transistors (5 V I/O devices).

This circuit has three main blocks, as shown in Figure 1. A current reference cell is used to generate a current that is proportional to absolute temperature (PTAT). A start-up circuit is used to initialize the current reference cell and stabilize its current at a nonzero value. Finally, the third block generates the temperature-independent voltage by first creating a voltage at node $V_{x}$ that is complementary to absolute temperature (CTAT). Resistor $R_{\text {out }}$ then combines the PTAT and CTAT signals into an overall output voltage that has very low temperature dependence. 
To achieve low power consumption, our circuit was designed to operate in the subthreshold region with very low bias currents. The drain current of a transistor biased in subthreshold can be expressed as [17]:

$$
I_{d}=I_{0}^{\prime} S e^{\frac{\kappa\left(V_{g}-V_{T}\right)}{u_{T}}}\left(e^{\frac{-V_{s}}{u_{T}}}-e^{\frac{-V_{d}}{u_{T}}}\right),
$$

where $I_{0}^{\prime}=\frac{2}{\kappa} \mu C_{o x} U_{T}^{2}, S$ is the aspect ratio $(W / L)$ of the transistor, $U_{T}=k T / q$ is the thermal voltage, $k$ is the Boltzmann constant, $q$ is the elementary charge, $T$ is the absolute temperature in kelvins, $V_{T}$ is the MOSFET threshold voltage, and $\kappa$ is the subthreshold slope coefficient representing the capacitive coupling from the gate to the surface potential $\left(\kappa=C_{o x} /\left(C_{o x}+C_{D}\right)\right)$. Voltages $V_{g}, V_{s}$, and $V_{d}$ are the gate, source, and drain voltages, respectively, referenced to the substrate. When the transistor operates in the saturation region, $\exp \left(\frac{-V_{d}}{U_{T}}\right)$ approaches zero and is, therefore, negligible. We also assume that the transistors have been designed with large-enough channel lengths that the channel-length modulation effect can be safely neglected.

The detailed operation of each block will be explained in the remainder of this section.

\subsection{Reference Current Generator}

We use a standard PTAT current generation block that includes a current source and a current mirror. The difference between the $V_{g s}$ values of $M_{10}$ and $M_{11}$ establishes a voltage across $R_{C}$. By proper sizing of $R_{C}, M_{10}$, and $M_{11}\left(S_{11}>S_{10}\right)$, all the transistors in the PTAT current generator can be biased to be in the subthreshold region. By setting $S_{6}=S_{7}$, the PMOS current mirror provides unity gain. Using Equation (1) to define expressions for the currents in $M_{10}$ and $M_{11}$, the current generated by $R_{C}$ is

$$
I_{R_{C}}=\frac{V_{s}}{R_{C}}=U_{T}\left(\frac{1}{R_{C}}\right) \ln \left(\frac{S_{11}}{S_{10}}\right)
$$

which linearly increases with temperature. $I_{R_{C}}$ is mirrored to $M_{12}$ and $M_{13}$ with ratios of $x$ and $y$. Thus, we have

$$
\begin{aligned}
& I_{x}=I_{12}=I_{14}=x I_{R_{C^{\prime}}} \\
& I_{y}=I_{13}=I_{t 2}=y I_{R_{C}} .
\end{aligned}
$$

Accordingly, the voltage drop across $R_{\text {out }}$ caused by the PTAT current source can be expressed as

$$
V_{P T A T}=y\left(\frac{k T}{q}\right)\left(\frac{R_{o u t}}{R_{C}}\right) \ln \left(\frac{S_{11}}{S_{10}}\right) .
$$

This voltage is PTAT and can be set by $R_{\text {out }} / R_{C}$ and the aspect ratios for $M_{10}$ and $M_{11}$

\subsection{Start-Up Circuit}

A start-up circuit is used to initialize the current reference cell and stabilize its current at a nonzero value $\left(I_{R_{C}} \neq 0\right)$. We use the start-up circuit presented by [18]. This start-up circuit turns on $M_{6}, M_{7}$, $M_{10}$, and $M_{11}$ at power-up to initialize a nonzero $I_{R_{C}}$. After a very short delay, $C_{s}$ is charged up to $V_{d d}$ through $M_{1}$, thereby turning off $M_{4}$ and $M_{5}$ so that they no longer inject current to the current generator. After the brief initialization period, the start-up circuit consumes no appreciable current and, therefore, does not add to the overall power consumption of the voltage reference cell.

\subsection{Temperature-Independent Voltage Reference Cell}

The temperature-independent voltage reference cell is based upon a modified version of the building block shown in Figure 2a that is commonly used as a PTAT voltage generator (e.g., [19]). 
The currents through $M_{b}$ and $M_{a}$ are $I_{x}$ and $I_{x}+I_{y}$, respectively. These two currents can be expressed using Equation (1) as

$$
\begin{gathered}
M_{b}: I_{x}=I_{0}^{\prime} S_{b} e^{\frac{\kappa\left(V_{g}-V_{T}\right)}{u_{T}}} e^{-\frac{V_{y}}{u_{T}}}, \\
M_{a}: I_{x}+I_{y}=I_{0}^{\prime} S_{a} e^{\frac{\kappa\left(V_{g}-V_{T}\right)}{u_{T}}}\left(1-e^{-\frac{V_{y}}{u_{T}}}\right) .
\end{gathered}
$$

By dividing Equation (7) by Equation (6) and solving for $V_{y}$, we find that

$$
V_{y}=U_{T} \ln \left(1+\left(\frac{S_{b}}{S_{a}}\right)\left(\frac{I_{x}+I_{y}}{I_{x}}\right)\right) .
$$

The resulting voltage is PTAT and can be set by proper sizing of $M_{a}$ and $M_{b}$ and the bias currents $\left(I_{x}\right.$ and $\left.I_{y}\right)$. However, the value of $V_{y}$ cannot be made large because of the log compression working on the ratio of the transistor sizes and currents. Some designs stack this circuit repeatedly to generate a higher reference voltage, as shown in Figure 2b, but they still struggle to achieve a high voltage [20].

Figure 2c shows a modification to Figure $2 \mathrm{a}$ that replaces the bottom transistor with a thick-oxide device. This configuration has been used previously to provide a low voltage at $V_{y}$ that is CTAT $[18,21,22]$. We, instead, use this configuration to help us achieve a much higher voltage at another node that is also CTAT.

The currents through $M_{b}$ and $M_{a t}$ follow the forms of Equations (6) and (7), with the only differences being the various process-dependent parameters for the thick-oxide device, $M_{a t}$,

$$
M_{a t}: I_{x}+I_{y}=I_{0 t}^{\prime} S_{a t} e^{\frac{\kappa_{t}\left(V_{g}-V_{T t}\right)}{u_{T}}}\left(1-e^{-\frac{V_{y}}{u_{T}}}\right),
$$

where the extra ' $t$ ' in the subscript represents the value for the thick-oxide device. By dividing Equation (9) by Equation (6) and solving for $V_{y}$, we obtain

$$
V_{y}=U_{T} \ln \left(1+\frac{I_{x}+I_{y}}{I_{x}} \frac{I_{0}^{\prime} S_{b}}{I_{0 t}^{\prime} S_{a t}} e^{\frac{\kappa_{T} V_{T t}-\kappa V_{T}}{U_{T}}} e^{\frac{\kappa V_{g}-\kappa_{t} V_{g}}{u_{T}}}\right) .
$$

Noting that $V_{T t}>V_{T}$ and that $\kappa V_{g}-\kappa_{t} V_{g} \approx 0$, Equation (10) can be approximated as

$$
V_{y} \approx \kappa_{t} V_{T t}-\kappa V_{T}+U_{T} \ln \left[\left(\frac{I_{x}+I_{y}}{I_{x}}\right)\left(\frac{I_{0}^{\prime} S_{b}}{I_{0 t}^{\prime} S_{a t}}\right)\right]
$$

with proper sizing of the transistors. $V_{T t}$ is typically several hundred $\mathrm{mV}$ greater than $V_{T}$, which means that using a thick-oxide transistor for $M_{a t}$ can produce a voltage at $V_{y}$ that is much larger than can be produced by Figure 2a. Additionally, $V_{y}$ is dominated by the first two terms of Equation (11), and since threshold voltages are widely known to be CTAT [23], $V_{y}$ is also a CTAT voltage.

Next, we show that we can use Figure $2 \mathrm{c}$ to create a CTAT voltage at the bottom of $R_{\text {out }}\left(V_{x}\right)$ in Figure 1. The current through $M_{t 1}$ can be expressed as

$$
I_{t 1}=\left(1+\frac{y}{x}\right) I_{14}
$$

Using Equations (11) and (12), the following equation can be achieved:

$$
V_{y} \approx \kappa_{t} V_{T t}-\kappa V_{T}+U_{T} \ln \left[\left(1+\frac{y}{x}\right)\left(\frac{I_{0}^{\prime} S_{14}}{I_{0 t}^{\prime} S_{t 1}}\right)\right] .
$$

Using Equation (13) and the equation for the current through $M_{t 2}$, the voltage at node $V_{x}$ can be expressed as

$$
V_{x}=2 V_{T t}-\frac{\kappa}{\kappa_{t}} V_{T}+\frac{U_{T}}{\kappa_{t}} \ln \left[\frac{\xi}{R_{c} T}\right],
$$


where

$$
\xi=\left(y+\frac{y^{2}}{x}\right) \frac{S_{14}}{S_{t 1} S_{t 2}} \ln \left(\frac{S_{11}}{S_{10}}\right) \frac{q}{k} \frac{\kappa_{t}^{2} C_{o x}}{2 \mu \kappa C_{o x t}^{2}} .
$$

$V_{x}$ is dominated by the first two terms of Equation (14), and, since threshold voltages are widely known to be CTAT [23], $V_{x}$ is a CTAT voltage.

Finally, $V_{\text {out }}$ is the summation of the PTAT voltage given by Equation (5) and the CTAT voltage given by Equation (14):

$$
\begin{gathered}
V_{\text {out }}=y R_{\text {out }} I_{R_{C}}+V_{x} \\
V_{\text {out }}=y \frac{R_{\text {out }}}{R_{C}} U_{T} \ln \left(\frac{S_{11}}{S_{10}}\right)+2 V_{T t}-\frac{\kappa}{\kappa_{t}} V_{T}+\frac{U_{T}}{\kappa_{t}} \ln \left[\frac{\xi}{R_{c} T}\right] .
\end{gathered}
$$

The goal of this voltage reference cell is to generate an above- $1 \mathrm{~V}$ output using thick-oxide transistors. The execution of this idea is visible in Equation (17), where $2 V_{T t}$ is a considerable portion of the output voltage. Additionally, the voltage drop across $R_{\text {out }}$ further increases $V_{\text {out }}$. Thus, using the proposed structure, a higher voltage can be achieved by using a small number of transistors and taking advantage of the thick-oxide transistor's larger threshold voltage.

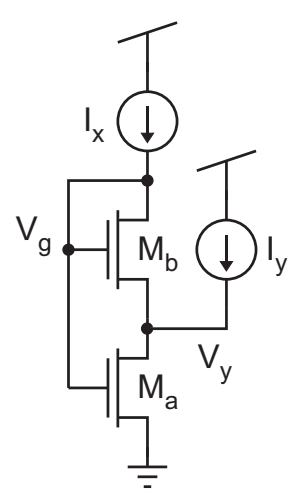

(a)

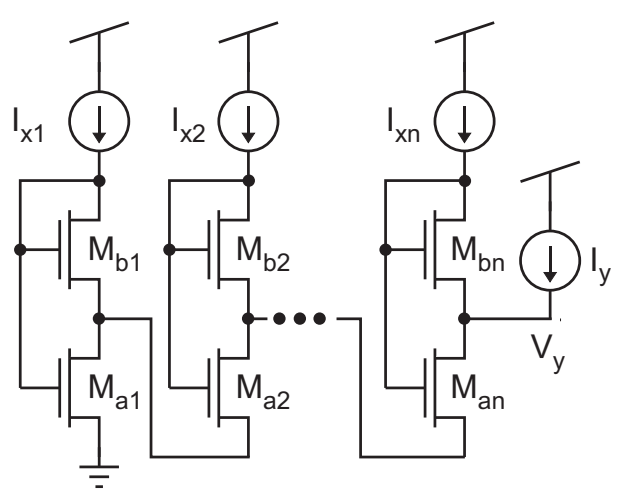

(b)

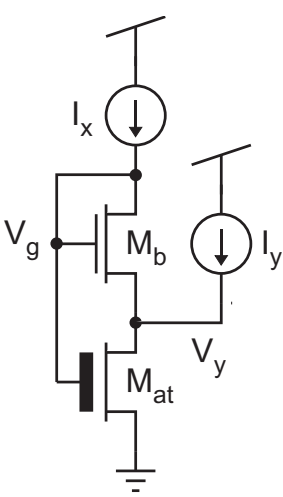

(c)

Figure 2. (a) A PTAT voltage generator; (b) generating a higher voltage through stacking PTAT voltage generators; (c) a CTAT voltage generator.

\section{Design Procedure for Low TC $V_{\text {out }}$}

In this section, we discuss how to design this voltage reference circuit to have a low temperature coefficient. By taking the derivative of Equation (17) with respect to $T$, we arrive at an equation for the TC at $V_{\text {out }}$ :

$$
T C=\frac{\partial V_{\text {out }}}{\partial T}=y \frac{k}{q} \frac{R_{\text {out }}}{R_{C}} \ln \left(\frac{S_{11}}{S_{10}}\right)+2 \alpha_{t}-\frac{\kappa}{\kappa_{t}} \alpha+\frac{k}{\kappa_{t} q}\left[\ln \left(\frac{\xi}{R_{c} T}\right)-1\right] .
$$

The $\alpha$ terms, which have a negative value, come from the commonly used expression for the temperature effects on the threshold voltage [23] given by

$$
V_{T}(T)=V_{T}\left(T_{0}\right)+\alpha\left(T-T_{0}\right),
$$

where $T_{0}$ is a reference temperature, and $T$ is the temperature of interest. The $\alpha$ terms are generally in the $\mathrm{mV} / \mathrm{K}$ range, with $\mathrm{I} / \mathrm{O}$ thick-oxide devices typically having larger values than thin-oxide devices.

Analyzing Equation (18), we can see that the temperature dependence of the resistors and their exact values have little impact on the TC; assuming both resistors are made from the same material, their temperature dependencies cancel in the first term. $R_{C}$ is also contained within the $\ln$ term, but its temperature effects have little impact since they are compressed by the logarithmic function; hence, 
the temperature effects of $R_{C}$ are neglected in this analysis (and they are far less significant than the $T$ term in the same $\ln$ function). The $\xi$ term also contains the temperature-dependent items $\mu, \kappa$, and $\kappa_{t}$; again, since they are logarithmically compressed, they have little impact on the overall TC, and their temperature effects can be safely neglected. The only other remaining temperature-dependent term in Equation (18) is $T$ within $\ln \left(\xi / R_{C} T\right)$. Since $T$ is within an $\ln$ function, its effect on the TC is significantly compressed, meaning that it is possible to achieve a low overall TC. To achieve a low TC over a temperature range of interest, a reference temperature in the middle of the range should be chosen; then, the TC can be minimized by setting Equation (18) equal to zero at that reference temperature, $T_{0}$. By then solving for $\ln \left(\xi / R_{C} T\right)$ and plugging that expression into Equation (17), we find the optimal value for $V_{\text {out }}$ :

$$
\begin{gathered}
V_{\text {out }, \text { optimal }}=2 V_{T t}-\frac{\kappa}{\kappa_{t}} V_{T}-2 \alpha_{t}\left(T_{0}\right)+\frac{\kappa}{\kappa_{t}} \alpha\left(T_{0}\right)+\frac{U_{T}}{\kappa_{t}}, \\
V_{\text {out }, \text { optimal }} \approx 2 V_{T t}-V_{T}-2 \alpha_{t}\left(T_{0}\right)+\alpha\left(T_{0}\right)+\frac{U_{T}}{\kappa_{t}} .
\end{gathered}
$$

Noting that the $\alpha$ terms have negative values (i.e., $V_{T}$ is CTAT) and are typically in the $\mathrm{mV} / \mathrm{K}$ range [23], the optimal $V_{\text {out }}$ at room temperature will be greater than $1 \mathrm{~V}$, particularly because of the reasonably high $V_{T}$ of $5 \mathrm{~V} \mathrm{I} / \mathrm{O}$ devices. An estimate for $V_{\text {out }, \text { optimal }}$ can be calculated from Equations (20) and (21) by obtaining values for $V_{T}, V_{T t}, \kappa, \kappa_{t}, \alpha$, and $\alpha_{t}$ from the simulation models. Accordingly, for our design, $V_{\text {out }, \text { optimal }} \approx 1.6 \mathrm{~V}$.

To minimize the TC, the output voltage of this circuit as given by Equation (17) should be designed to equal $V_{\text {out,optimal }}$. The use of the resistive ratio $R_{\text {out }} / R_{C}$ greatly simplifies this design consideration. Once again, we note that the transistor aspect ratios in Equation (17) are primarily within ln functions, so the ratio of $R_{\text {out }} / R_{C}$ plays an important factor in establishing the correct $V_{\text {out }}$. To determine the best ratio for $R_{\text {out }} / R_{C}$ to minimize the TC, Equations (17) and (20) can be equated, and the best resistor ratio can be found to be

$$
y \frac{R_{\text {out }}}{R_{C}}=\frac{\frac{1}{\kappa_{t}}\left[1-\ln \left(\frac{\xi}{R_{C} T_{0}}\right)\right]-\frac{q}{k}\left(2 \alpha_{t}-\alpha\right)}{\ln \left(\frac{S_{11}}{S_{10}}\right)} .
$$

In our design, a ratio of $R_{\text {out }} / R_{C} \approx 6$ is needed to achieve a good TC and, accordingly, cause $V_{\text {out }} \approx V_{\text {out }, \text { optimal }}$. Additionally, by changing the resistive ratio slightly, the temperature at which the TC is minimized can be shifted to a higher or lower value while still maintaining a good TC. Of note, our implementation utilized discrete off-chip resistors, limiting our ability to exactly achieve $V_{\text {out,optimal }}$, and the resulting TC was still low. Varying the resistor ratio is explored further in Section 4.

Next, we present a design procedure to obtain a low-TC, above- $1 \mathrm{~V}$ voltage reference cell using the circuit of Figure 1.

1. Set $\frac{S_{11}}{S_{10}} \gg 1$, and choose a proper size for $R_{C}$ to bias the current reference cell in subthreshold. Note that increasing $\frac{S_{11}}{S_{10}}$ will necessitate a larger $R_{C}$ in order to bias the circuit in subthreshold, so area limitation requirements for the circuit can be used to set a maximum value of $\frac{S_{11}}{S_{10}}$.

2. Choose appropriate transistor aspect ratios such that $\frac{S_{14}}{S_{t 1} S_{t 2}} \geq 1$ and also that $x$ and $y$ keep all transistors in the subthreshold. These design choices make it possible to approximate Equation (10) with Equation (11).

3. Ensure that all transistor lengths are large enough to neglect the effects of channel-length modulation.

4. Choose the midpoint, $T_{0}$, of the desired temperature range, and use Equation (22) to solve for $y \frac{R_{\text {out }}}{R_{C}}$.

5. If the midpoint of the $V_{\text {out }}$ vs. $T$ curve is not at the desired location, then, according to Equation (22), we can adjust $R_{C}$ to move $T_{0}$ to higher or lower temperatures. In addition, 
$R_{\text {out }}$ must be adjusted, accordingly, to keep the resistive ratio at a reasonable value, based on Equation (22).

\section{Experimental Results}

The voltage reference circuit of Figure 1 was fabricated using a standard $0.35 \mu \mathrm{m}$ CMOS technology and operates on a $3.3 \mathrm{~V}$ supply. Table 1 provides details of the transistor sizes. A die photograph of this circuit is shown in Figure 3. The die area of this circuit, excluding the resistors, was $0.033 \mathrm{~mm}^{2}$. The resistors $\left(R_{C}\right.$ and $\left.R_{\text {out }}\right)$ used in this circuit were off-chip resistors to allow for variety of $R_{\text {out }} / R_{C}$ combinations. Using the design procedure of Section 3, we found that $R_{\text {out }} / R_{C} \approx 6$ for a low TC output. $R_{\text {out }}$ and $R_{C}$ were set to $3 \mathrm{M} \Omega$ and $500 \mathrm{k} \Omega$, respectively, to achieve this ratio and to ensure subthreshold operation. These values were also chosen to minimize the TC around room temperature. If the resistors that we used in our experiments were integrated on chip, the die area would increase to $0.06 \mathrm{~mm}^{2}$. Future implementations of this circuit would include on-chip resistors; basic trimming capabilities can be used to modify both the resistor values and resistor ratio to meet the required $V_{\text {out }}$ and TC. One simple and conventional approach for trimming in a standard CMOS process is to create a series combination of smaller resistor values, each of which can be shorted out through digital selection to achieve the desired resistance.

Table 1. Device sizes used in our design.

\begin{tabular}{cc}
\hline Device (s) & Size \\
\hline$M_{1}-M_{5}$ & $5 \mu \mathrm{m} \times 1 \mu \mathrm{m}$ \\
\hline$M_{6}-M_{7}$ & $20 \mu \mathrm{m} \times 20 \mu \mathrm{m}$ \\
\hline$M_{8}-M_{10}$ & $4 \mu \mathrm{m} \times 2 \mu \mathrm{m}$ \\
\hline$M_{11}$ & $40 \mu \mathrm{m} \times 2 \mu \mathrm{m}$ \\
\hline$M_{12}$ & $20 \mu \mathrm{m} \times 20 \mu \mathrm{m}$ \\
\hline$M_{13}$ & $40 \mu \mathrm{m} \times 20 \mu \mathrm{m}$ \\
\hline$M_{14}$ & $4 \mu \mathrm{m} \times 20 \mu \mathrm{m}$ \\
\hline$M_{t 1}-M_{t 2}$ & $200 \mu \mathrm{m} \times 10 \mu \mathrm{m}$ \\
\hline$C_{S}$ & $3.1 \mathrm{pF}$ \\
\hline
\end{tabular}

A Tenney TUJR environmental chamber was used to measure the performance of this circuit under varying temperatures; this environmental chamber has a temperature range of $-75^{\circ} \mathrm{C}$ to $200^{\circ} \mathrm{C}$. Figure $4 \mathrm{a}$, b shows the measured $V_{\text {out }}$ over temperature for multiple values of $V_{D D}$. Figure $4 \mathrm{~b}$ shows that this circuit is able to achieve a low $\mathrm{TC}$ of $42 \mathrm{ppm} /{ }^{\circ} \mathrm{C}$ over the temperature range of interest $(-70$ to $+85^{\circ} \mathrm{C}$ ). Even extending this temperature range significantly to cover from -70 to $+125^{\circ} \mathrm{C}$, this circuit can still achieve a TC of $110 \mathrm{ppm} /{ }^{\circ} \mathrm{C}$ at the nominal $V_{D D}=3.3 \mathrm{~V}$ (see Figure 4a). By reducing $V_{D D}$ to $1.7 \mathrm{~V}$, the $\mathrm{TC}$ is $48 \mathrm{ppm} /{ }^{\circ} \mathrm{C}$ over this extended temperature range. 


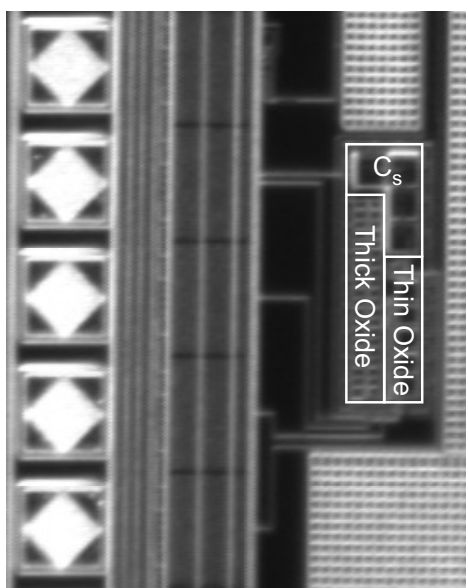

Figure 3. Die photograph of the proposed circuit. The single capacitor $\left(C_{s}\right)$, the thick-oxide transistors, and the thin-oxide transistors are all delineated in this die photograph. The two resistors were included as off-chip components. The size of this voltage reference cell (excluding the resistors) was $300 \mu \mathrm{m} \times 110 \mu \mathrm{m}$.

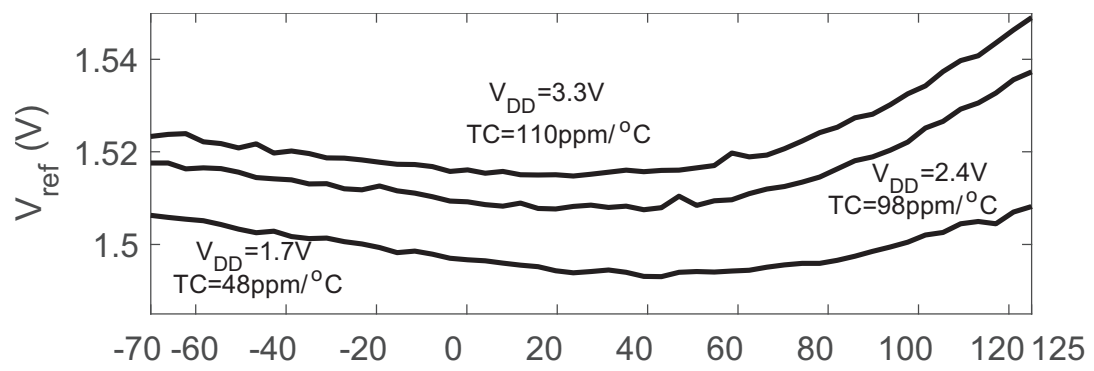

(a)

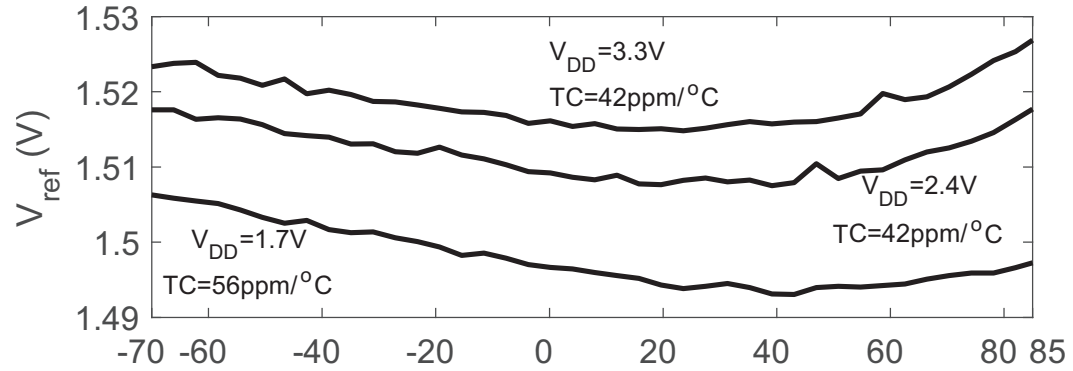

(b)

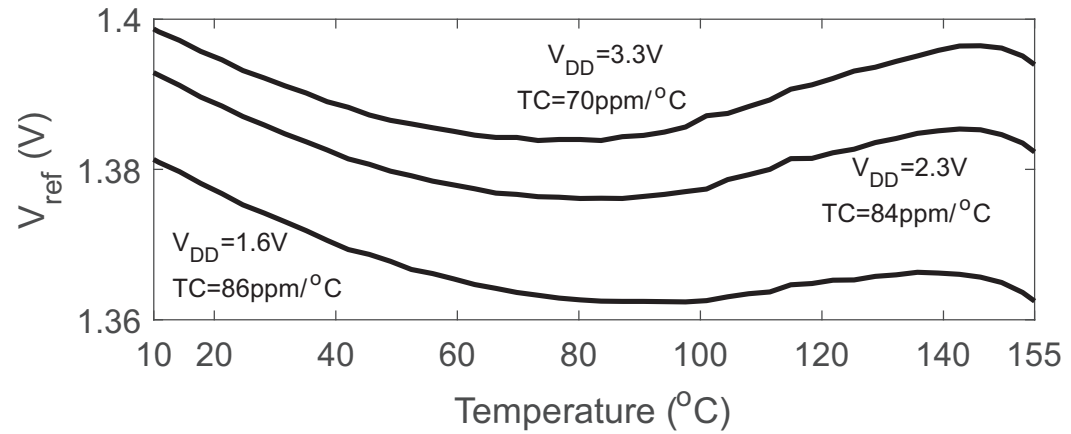

(c)

Figure 4. Measured TC of the proposed circuit under three different supply values for multiple conditions. (a) $R_{\text {out }} / R_{\mathrm{C}}=3 \mathrm{M} \Omega / 500 \mathrm{k} \Omega$ from -70 to $+125^{\circ} \mathrm{C} ;(\mathbf{b}) R_{\text {out }} / R_{\mathrm{C}}=3 \mathrm{M} \Omega / 500 \mathrm{k} \Omega$ from -70 to $+85^{\circ} \mathrm{C}$; (c) $R_{\text {out }} / R_{\mathrm{C}}=2 \mathrm{M} \Omega / 400 \mathrm{k} \Omega$ from +10 to $+155^{\circ} \mathrm{C}$. 
As discussed in the previous section, this circuit can be optimized to achieve a good TC for different temperature ranges. Figure $4 \mathrm{c}$ shows an example of shifting the midpoint of the temperature range to a higher value. This midpoint reference temperature can be increased by setting $R_{\text {out }} / R_{C}$ to a smaller value and by also reducing the value of $R_{C}$, as is evidenced by Equation (18). In this example, $R_{C}$ was reduced to $400 \mathrm{k} \Omega$, which increases the temperature midpoint, $T_{0}$, due to the $\ln \left(\xi / R_{C} T\right)$ term. $R_{\text {out }}$ was also decreased to $2 \mathrm{M} \Omega$ to keep the resistor ratio similar (but slightly smaller). The result is that the same circuit, with different resistor values, can be used to provide a low TC $\left(70 \mathrm{ppm} /{ }^{\circ} \mathrm{C}\right.$ at $\left.V_{D D}=3.3 \mathrm{~V}\right)$ at higher temperatures $\left(+10\right.$ to $\left.+155^{\circ} \mathrm{C}\right)$. Under this condition, the output voltage was $V_{\text {out }}=1.395 \mathrm{~V}$, and, if the resistors were integrated on-chip, then the area would be $0.044 \mathrm{~mm}^{2}$.

The measured supply current versus temperature for these two reference voltages $\left(V_{\text {out }}=1.52 \mathrm{~V}\right.$, $1.395 \mathrm{~V})$ under a $3.3 \mathrm{~V}$ supply is shown in Figure 5. The power consumption of this circuit at room temperature for the two $R_{\text {out }} / R_{\mathrm{C}}$ conditions were $1.11 \mu \mathrm{W}\left(V_{\text {out }}=1.52 \mathrm{~V}\right)$ and $1.34 \mu \mathrm{W}\left(V_{\text {out }}=1.395 \mathrm{~V}\right)$. Thus, this circuit is an appropriate choice for low-power applications.

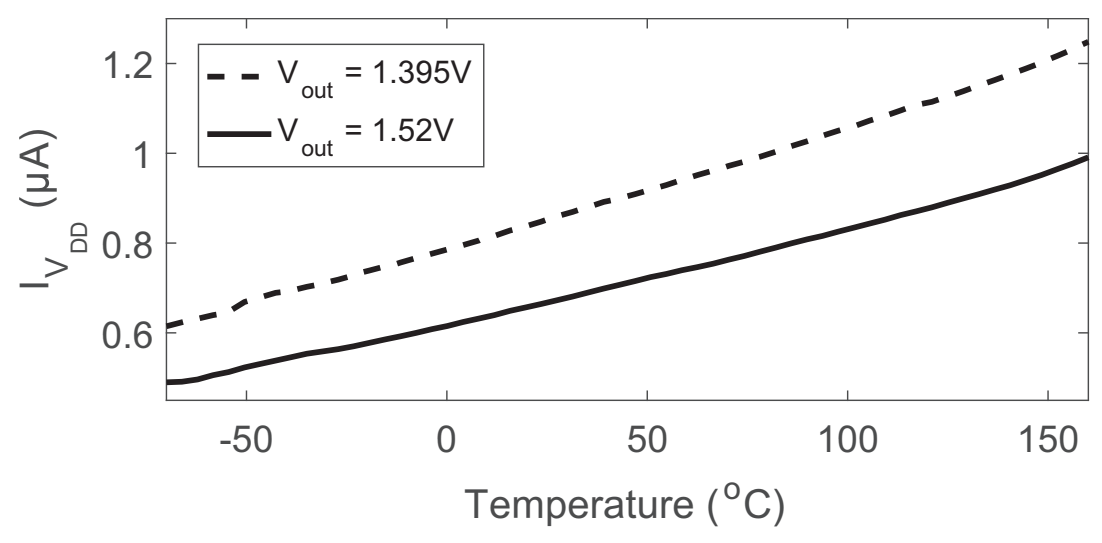

Figure 5. Measured supply current.

The line regulation of the circuit was measured at room temperature by sweeping the supply voltage from $0 \mathrm{~V}$ to $3.3 \mathrm{~V}$, as shown in Figure 6 . The line regulation for the two $R_{\text {out }} / R_{\mathrm{C}}$ conditions of Figure 4 were $10 \mathrm{mV} / \mathrm{V}\left(V_{\text {out }}=1.52 \mathrm{~V}\right)$ and $9.3 \mathrm{mV} / \mathrm{V}\left(V_{\text {out }}=1.395 \mathrm{~V}\right)$. The line regulation can be significantly improved by cascoding the PMOS transistors $M_{6}, M_{7}, M_{12}$, and $M_{13}$ at the expense of a higher minimum supply voltage. Simulation results show that using a cascode structure would improve the line regulation to $2.88 \mathrm{mV} / \mathrm{V}$ and would only degrade the supply range by approximately $100 \mathrm{mV}$. The limited $V_{D D \text {, min }}$ of this circuit was due to the high output voltage of the circuit. In both $R_{\text {out }} / R_{C}$ cases, $V_{D D \text {, min }}$ was approximately $V_{D D \text {, min }} \approx V_{\text {out }}+200 \mathrm{mV}$ (and would be approximately $V_{\text {out }}+300 \mathrm{mV}$ if cascoded PMOS devices were used to improve the line regulation).

The measured power supply rejection ratios (PSRR) at $100 \mathrm{~Hz}$ were $-35 \mathrm{~dB}\left(V_{\text {out }}=1.52 \mathrm{~V}\right)$ and $-37.9 \mathrm{~dB}\left(V_{\text {out }}=1.395 \mathrm{~V}\right)$. The PSRR values at $1 \mathrm{MHz}$ were $-44 \mathrm{~dB}\left(V_{\text {out }}=1.52 \mathrm{~V}\right)$ and $-44.8 \mathrm{~dB}$ $\left(V_{\text {out }}=1.395 \mathrm{~V}\right)$.

The die-to-die distribution of the DC output voltage was found at room temperature by measuring the average reference voltage $(\mu)$ and the standard deviation $(\sigma)$ for 17 available chips. The coefficient of variation $(\sigma / \mu)$ for the $1.52 \mathrm{~V}$ and $1.395 \mathrm{~V}$ outputs were $2 \%$ and $1.76 \%$, respectively.

Table 2 compares the three cases of our voltage reference circuit shown in Figure 4 to other similar circuits. Specifically, we compared our work to other circuits that (1) were fabricated; (2) were in a CMOS process; (3) have $V_{\text {out }} \geq 1 \mathrm{~V}$; and (4) have power consumption $\leq 50 \mu \mathrm{W}$. As can be seen from this table, our voltage reference circuit is able to provide a good balance of a low TC, low power consumption, and a large range of temperatures. Additionally, our circuit only uses devices available in standard CMOS processes (thicker-oxide I/O devices are now widely available), whereas some of the listed designs require non-standard devices $[13,15]$. 
Table 2. Comparison of the proposed work with other works.

\begin{tabular}{|c|c|c|c|c|c|c|c|c|c|c|}
\hline & Process & $\begin{array}{c}\text { Temperature Coefficient } \\
\left(\mathrm{ppm} /{ }^{\circ} \mathrm{C}\right)\end{array}$ & $\begin{array}{l}\text { Temperature } \\
\text { Range }\end{array}$ & $V_{R E F}$ & $\begin{array}{l}\text { Line Regulation } \\
\qquad(\mathrm{mV} / \mathrm{V})\end{array}$ & $\begin{array}{c}\text { PSRR } \\
\text { (dB) }\end{array}$ & $V_{D D}$ & Power & $\begin{array}{c}\text { Area } \\
\left(\mathrm{mm}^{2}\right)\end{array}$ & Comments \\
\hline$[8]$ & $0.6 \mu \mathrm{m}$ & 14.36 & [0 100] & $1.2525 \mathrm{~V}$ & 5.5 & $-42 \mathrm{~dB} @ 10 \mathrm{MHz}$ & $1.5 \sim 2$ & $40 \mu \mathrm{W}$ & 0.11 & - \\
\hline [9] & $0.35 \mu \mathrm{m}$ & 12.85 & [5 95] & $1.2 \mathrm{~V}$ & 28 & $-26.2 \mathrm{~dB} @ 100 \mathrm{~Hz}$ & $1.75 \sim 3.5$ & $35.7 \mu \mathrm{W}$ & 0.0206 & - \\
\hline [13] & $0.18 \mu \mathrm{m}$ & $8-73$ & [0 100] & $1.25 \mathrm{~V}$ & 0.31 & $-41 \mathrm{~dB} @ 100 \mathrm{~Hz}$ & $1.4 \sim 3.6$ & $35 \mathrm{pW}$ & 0.0025 & Native NFETs \\
\hline [15] & $0.18 \mu \mathrm{m}$ & 4.1 & {$\left[\begin{array}{lll}-5 & 125\end{array}\right]$} & $1.1402 \mathrm{~V}$ & 0.3 & -54 dB@ $100 \mathrm{~Hz}$ & $1.3 \sim 2.6$ & $11.18 \mu \mathrm{W}$ & 0.05 & NPN BJTs \\
\hline [19] & $0.35 \mu \mathrm{m}$ & $215-394$ & {$\left[\begin{array}{ll}-20 & 80\end{array}\right]$} & $1.18 \mathrm{~V}$ & 4.5 & - & $1.3 \sim 3.3$ & $0.108 \mu \mathrm{W}$ & 0.21 & - \\
\hline [24] & $0.25 \mu \mathrm{m}$ & 627 & [20 50] & $0.71-1.03 \mathrm{~V}$ & 0.2 & $-51 \mathrm{~dB} @ 100 \mathrm{~Hz}$ & $1.5 \sim 3.5$ & $0.12 \mu \mathrm{W}$ & 0.011 & - \\
\hline [25] & $0.18 \mu \mathrm{m}$ & 147 & {$\left[\begin{array}{lll}-40 & 120\end{array}\right]$} & $1.09 \mathrm{~V}$ & - & -62 dB @ $100 \mathrm{~Hz}$ & $1.2 \sim 1.8$ & $0.1 \mu \mathrm{W}$ & 0.0294 & - \\
\hline [26] & $0.18 \mu \mathrm{m}$ & 4 & [0 100] & $1.012 \mathrm{~V}$ & 0.5 & $-66 \mathrm{~dB} @ 1 \mathrm{kHz}$ & $1.1 \sim 1.8$ & $21 \mu \mathrm{W}$ & - & - \\
\hline This work \#1 & $0.35 \mu \mathrm{m}$ & $110 @ 3.3 \mathrm{~V}$ & {$\left[\begin{array}{lll}-70 & 125\end{array}\right]$} & $1.52 \mathrm{~V}$ & 10 & $-44 \mathrm{~dB} @ 1 \mathrm{MHz}$ & $1.7 \sim 3.3$ & $1.11 \mu \mathrm{W}$ & 0.06 & - \\
\hline This work \#1 & $0.35 \mu \mathrm{m}$ & $42 @ 3.3 \mathrm{~V}$ & {$\left[\begin{array}{lll}-70 & 85\end{array}\right]$} & $1.52 \mathrm{~V}$ & 10 & $-44 \mathrm{~dB} @ 1 \mathrm{MHz}$ & $1.7 \sim 3.3$ & $1.11 \mu \mathrm{W}$ & 0.06 & - \\
\hline This work \#2 & $0.35 \mu \mathrm{m}$ & $70 @ 3.3 \mathrm{~V}$ & [10 160] & $1.395 \mathrm{~V}$ & 9.33 & $-44.8 \mathrm{~dB} @ 1 \mathrm{MHz}$ & $1.6 \sim 3.3$ & $1.34 \mu \mathrm{W}$ & 0.044 & - \\
\hline
\end{tabular}




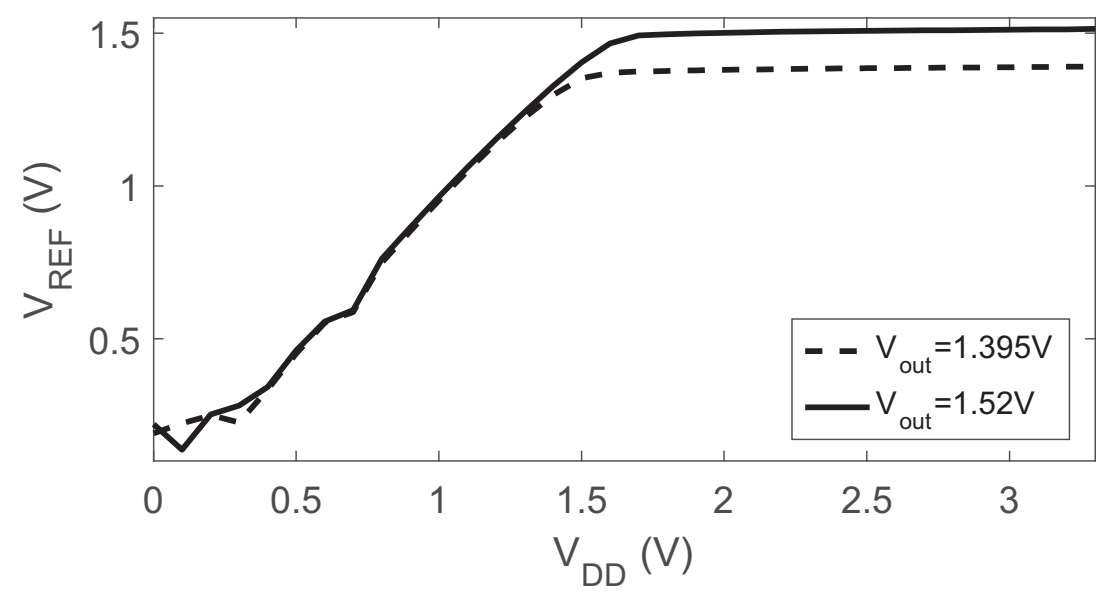

Figure 6. Measured line regulation.

\section{Conclusions}

A low power voltage reference cell for system-on-a-chip applications has been presented in this paper. This proposed cell uses a combination of thin-oxide and thick-oxide transistors to generate a reference voltage greater than $1 \mathrm{~V}$ with a low TC. We also presented a design methodology for how to translate this circuit to other processes and to provide a low-power and low-TC reference voltage.

Author Contributions: Both authors were responsible for designing the circuit and writing the paper. M.M.N. was responsible for all the experimental measurements.

Funding: This research was funded by the National Science Foundation grant number 1148815.

Acknowledgments: This material is based upon work supported by the National Science Foundation under Award No. 1148815.

Conflicts of Interest: The funding sponsors had no role in the design of the study; in the collection, analyses, or interpretation of data; in the writing of the manuscript; and in the decision to publish the results.

\section{References}

1. Vita, G.D.; Iannaccone, G. A sub-1-V, $10 \mathrm{ppm} /{ }^{\circ} \mathrm{C}$, nanopower voltage reference generator. IEEE J. Solid-State Circuits 2007, 42, 1536-1542. [CrossRef]

2. Ueno, K.; Hirose, T.; Asai, T.; Amemiya, Y. A $300 \mathrm{nW}, 15 \mathrm{ppm} /{ }^{\circ} \mathrm{C}, 20 \mathrm{ppm} / \mathrm{V}$ CMOS voltage reference circuit consisting of subthreshold MOSFETs. IEEE J. Solid-State Circuits 2009, 44, 2047-2054. [CrossRef]

3. Ivanov, V.; Gerber, J.; Brederlow, R. An ultra low power bandgap operational at supply as low as $0.75 \mathrm{~V}$. In Proceedings of the European Solid-State Circuits Conference, Helsinki, Finland, 12-16 September 2011; pp. 515-518.

4. Lee, K.K.; Lande, T.S.; Häfliger, P.D. A sub- $\mu \mathrm{W}$ bandgap reference circuit with an inherent curvature-compensation property. IEEE Trans. Circuits Syst. I Regul. Pap. 2015, 62, 1-9. [CrossRef]

5. Shrivastava, A.; Craig, K.; Roberts, N.E.; Wentzloff, D.D.; Calhoun, B.H. A $32 \mathrm{nW}$ bandgap reference voltage operational from $0.5 \mathrm{~V}$ supply for ultra-low power systems. In Proceedings of the IEEE International Solid-State Circuits Conference, San Francisco, CA, USA, 22-26 February 2015; pp. 94-95.

6. Liu, L.; Mu, J.; Zhu, Z. A 0.55-V, 28-ppm $/{ }^{\circ} \mathrm{C}, 83-\mathrm{nW}$ CMOS sub-BGR with ultralow power curvature compensation. IEEE Trans. Circuits Syst. I Regul. Pap. 2018, 65, 95-106. [CrossRef]

7. Rumberg, B.; Graham, D.W.; Clites, S.; Kelly, B.M.; Navidi, M.M.; Dilello, A.; Kulathumani, V. RAMP: Accelerating wireless sensor hardware design with a reconfigurable analog/mixed-signal platform. In Proceedings of the 14th International Conference on Information Processing in Sensor Networks, Seattle, WA, USA, 13-16 April 2015; pp. 47-58.

8. Leung, C.; Leung, K.; Mok, P. Design of a 1.5-V high-order curvature-compensated CMOS bandgap reference. In Proceedings of the IEEE International Symposium on Circuits and Systems, Vancouver, BC, Canada, 23-26 May 2004; Volume 1, pp. 48-52. 
9. Lam, Y.; Ki, W. CMOS bandgap references with self-biased symmetrically matched current-voltage mirror and extension of sub-1-V design. IEEE Trans. Very Large Scale Integr. VLSI Syst. 2010, 18, 857-865. [CrossRef]

10. Ge, G.; Zhang, C.; Hoogzaad, G.; Makinwa, K.A.A. A single-trim CMOS bandgap reference with a $3 \sigma$ inaccuracy of $\pm 0.15 \%$ from $-40{ }^{\circ} \mathrm{C}$ to $125^{\circ} \mathrm{C}$. IEEE J. Solid-State Circuits 2011, 46, 2693-2701. [CrossRef]

11. Ming, X.; Ma, Y.; Zhou, Z.; Zhang, B. A high-precision compensated CMOS bandgap voltage reference without resistors. IEEE Trans. Circuits Syst. II Exp. Briefs 2010, 57, 767-771. [CrossRef]

12. Al-Shyoukh, M.; Kalnitsky, A. A 500 nA quiescent current, trim-free, 1.75\% absolute accuracy, CMOS-only voltage reference based on anti-doped N-channel MOSFETs. In Proceedings of the IEEE 2014 Custom Integrated Circuits Conference, San Jose, CA, USA, 15-17 September 2014; pp. 1-4.

13. Lee, I.; Sylvester, D.; Blaauw, D. A subthreshold voltage reference with scalable output voltage for low-power IoT systems. IEEE J. Solid-State Circuits 2017, 52, 1443-1449. [CrossRef]

14. Ji, Y.; Jeon, C.; Son, H.; Kim, B.; Park, H.; Sim, J. A 9.3 nW all-in-one bandgap voltage and current reference circuit. In Proceedings of the IEEE International Solid-State Circuits Conference, San Francisco, CA, USA, 5-9 February 2017; pp. 100-101.

15. Wang, B.; Law, M.; Bermak, A. A precision CMOS voltage reference exploiting silicon bandgap narrowing effect. IEEE Trans. Electron Devices 2015, 62, 2128-2135. [CrossRef]

16. Lee, J.; Ji, Y.; Choi, S.; Cho, Y.; Jang, S.; Choi, J.; Kim, B.; Park, H.; Sim, J. A 29 nW bandgap reference circuit. In Proceedings of the IEEE International Solid-State Circuits Conference, San Francisco, CA, USA, 22-26 February 2015; pp. 1-3.

17. Enz, C.C.; Krummenacher, F.; Vittoz, E.A. An analytical MOS transistor model valid in all regions of operation and dedicated to low-voltage and low-current applications. Analog Integr. Circuits Signal Process. 1995, 8, 83-114. [CrossRef]

18. Yan, W.; Li, W.; Liu, R. Nanopower CMOS sub-bandgap reference with $11 \mathrm{ppm} /{ }^{\circ} \mathrm{C}$ temperature coefficient. Electron. Lett. 2009, 45, 627-629. [CrossRef]

19. Hirose, T.; Ueno, K.; Kuroki, N.; Numa, M. A CMOS bandgap and sub-bandgap voltage reference circuits for nanowatt power LSIs. In Proceedings of the IEEE Asian Solid-State Circuits Conference, Beijing, China, 8-10 November 2010; pp. 1-4.

20. Enz, C.; Vittoz, E. CMOS low-power analog circuit design. In Emerging Technologies: Designing Low Power Digital Systems; IEEE: New York, NY, USA, 1996; pp. 79-133.

21. Chiang, Y.; Liu, S. Nanopower CMOS relaxation oscillators with sub- $100 \mathrm{ppm} /{ }^{\circ} \mathrm{C}$ temperature coefficient. IEEE Trans. Circuits Syst. II Exp. Briefs 2014, 61, 661-665. [CrossRef]

22. Chatterjee, B.; Modak, N.; Amaravati, A.; Mistry, D.; Das, D.; Baghini, M. A sub-1 V, 120 nW, PVT-variation tolerant, tunable, and scalable voltage reference with 60-dB PSNA. IEEE Trans. Nanotechnol. 2017, 16, 406-410.

23. Tsividis, Y. Operation and Modeling of the MOS Transistor; McGraw-Hill: New York, NY, USA, 1987.

24. Chang, S.; AlAshmouny, K.; Yoon, E. A $1.5 \mathrm{~V} 120 \mathrm{nW}$ CMOS programmable monolithic reference generator for wireless implantable system. In Proceedings of the IEEE International Conference of Engineering in Medicine and Biology Society, Boston, MA, USA, 30 August-3 September 2011; pp. 2981-2984.

25. Osaki, Y.; Hirose, T.; Kuroki, N.; Numa, M. 1.2-V supply, 100-nW, 1.09-V bandgap and 0.7-V supply, 52.5-nW, 0.55-V sub-bandgap reference circuits for nanowatt CMOS LSIs. IEEE J. Solid-State Circuits 2013, 48, 1530-1538. [CrossRef]

26. Becker-Gomez, A.; Viswanathan, T.L.; Viswanathan, T.R. A low-supply-voltage CMOS sub-bandgap reference. IEEE Trans. Circuits Syst. II Exp. Briefs 2008, 55, 609-613. [CrossRef]

(c) 2018 by the authors. Licensee MDPI, Basel, Switzerland. This article is an open access article distributed under the terms and conditions of the Creative Commons Attribution (CC BY) license (http://creativecommons.org/licenses/by/4.0/). 